\title{
PHOTOGRAPHIC SCIENCE AND TECHNIQUE
}

A CONFERENCE on photographic science and technique was held by the Scientific and Technical Group of the Royal Photographic Society on May 16 in the Arthur Worthington Hall of the University of Manchester. Dr. G. N. Burkhardt (Department of Chemistry, University of Manchester) opened the proceedings, and the chairmen of the morning and afternoon sessions were Mr. V. Gallafent (Scientific and Technical Group of the Royal Photographic Society) and Mr. C. W. Bradley (British Cotton Industry Research Association). The success of the conference was attributable in a large measure to the contributions from the Manchester area, and the self-restraint of speakers in keeping to their allotted times.

The first paper was not directly related to photography, but dealt with the legibility of print when projected from 31 -in. square lantern slides. This clearly is a matter of importance to audiences, particularly at scientific meetings, for as Dr. R. Ollerenshaw (Manchester Royal Infirmary) pointed out there is evidence that the average eyesight of undergraduates is inferior to that of the eighteen-year-old National Service entrants and deteriorates during university residence. Whatever the form of the lettering, the illumination of the screen should be high, the contrast between the lettering and background strong, and preferably with the letters white on black. The greatest distance at which members of the audience should be seated should be six times the width of the screen (owing to the limited acuity of the eye) and the nearest distance twice the width of the screen (otherwise a tiresome rotation of the head itself must supplement the normal movement of the eyes). The seats should be grouped within a triangle of $60^{\circ}$ angle with its apex at the centre of the screen.

A study of type faces shows that upper-case Gill Sans Bold is best for acuity, readability and speed of reading. The italic form is useful for ordinate legends to graphs. The individual characters should be not less than $2 \mathrm{~mm}$. high on the slide, and lower-case type should be used only when this condition can be met. It has been found best to do all lettering with a small printing-press, a process which is at least as quick as good stencilling. The gap between lines of type should be equal to the body height of the type, and, as far as possible, each line should carry one item of the message. Diagrams and lettering in journals and books cannot well be used for lantern slides, or vice versa.

P. C. Smethurst (Smethurst High-Light, Ltd., Bolton) discussed the use of supplementary lenses with a telecentric stop. If a positive supplementary lens is arranged so that its rear principal focus is at the front nodal point of the camera lens, all the principal rays in the object space are parallel to the axis. The photograph then displays perspective such as would be obtained if the objects photographed were at infinity, and all measures of size on it are relatively correct, whatever the distances of the objects. The same device thus avoids the necessity for exact location of objects along the axis when it is important to measure sizes. Variations in perspective are obtained by placing the supplementary lens at other positions along the axis, so that the poncil of principal rays in the object space is divergent or convergent. A double system, sometimes useful, is obtained when a supplementary lens (a telescope objective) is used in the same way on each side of a camera objective.

The illumination of deep and narrow cavities by means of a concave mirror reflecting light from a lamp set to one side was then described by $\mathrm{F}$. Wardlaw (Christie Hospital, Manchester). Photographs are taken through a central aperture in the mirror, the subject being observed by means of a two-mirror periscope of which the first mirror is a thin sheet of unsilvered glass. The aberrations of a concave mirror used at an angle help to smooth out the image of the lamp filament, and for the same reason high optical quality is not necessary, but care should be taken to keep light off the front edges of the cavity by suitable focusing.

Dr. H. J. J. Braddick (Department of Physics, University of Manchester) pointed out that the photography of tracks in cloud chambers involves contradictory requirements. For example, the minimum delay between the arrival of a particle and the expansion is $10 \mathrm{msec}$. Then a period up to $250 \mathrm{msec}$. is required for the water drops to grow. The shorter this period can be, the more nearly will the water drops represent the particle track; but the longer they are allowed to grow, the brighter will the track be. It is, of course, difficult to get adequate illumination because the camera lens must be stopped down to get a fair depth of the chamber sharp in the photograph. In order to get adequate illumination, high-power flash tubes or heavily over-run tungsten lamps are used. Practical trial indicates that prolonged development increases the effective speed of the photographic material - a result which, from the discussion following the paper, was not unexpected by the photographic experts. If the inevitable delay between the arrival of a particle and the expansion is increased, and an electric field is established across the chamber, the positive and negative ions separate, forming two parallel tracks from the intensities of which the relative concentrations of ions of the two signs may be estimated. This technique is not possible with nuclear track plates.

In discussing the distortion of tracks in plates for recording nuclear particles, J. V. Major (University of Manchester) said that measurements indicate that there are two components, one centrally symmetrical and the other like a shear across the plate. Uneven drying (from the edges inwards) can account for part of the distortion, but the origin of the remainder is not clear. Temperature gradients during development may be responsible.

E. W. H. Selwyn (Kodak, Ltd.) considered progress in the physics of the developed image. Our qualitative knowledge of the make-up of the characteristic curve, of granularity, graininess, resolving power and sharpness, is fairly good, though there are still outstanding problems, and little quantitative 
information is available. Fuller details are available in the Journal of Photographic Science, 1, 60 (1953).

Methods of high-speed photography, based on dissection of the image, were then described by Dr. J. S. Courtney-Pratt (University of Cambridge). If a plate embossed with a large number of lenses is placed near the focal plane of a camera, a series of images of the camera lens will be formed on the sensitive material, and these taken all together form a picture of what is in front of the camera, rather like a half-tone illustration. When a small aperture is moved across the camera lens, a continuous line of overlapping small images is formed behind each element of the lenticular screen, thus recording any movement in the objects in front of the camera. In practice, a series of apertures is used, like the original Baird scanning disk for television, and each lenticular element produces a 'raster'. The fundamental advantage of this system is that the speed of the scanning disk, being simple rotation, may be made very high, and with bright enough (for example, self-luminous) subjects records may be obtained at the rate of $4 \mathrm{million} / \mathrm{sec}$. The same system reversed may be used for 'unscrambling' in slow motion or statically. A complete description, including variations on the above principle, is given in the Journgl of Photographic Science, 1, 21 (1953).

C. Burns (British Iron and Steel Research Association) described how the problem of recording the very fast motion of lumps of material swirling round in the hollow just beyond the tuyères in blast furnaces was dealt with. Stereoscopic motion pictures were made using two ports into a tuyère and a mirror system to produce the necessary pairs of pictures side by side on each frame of a $16-\mathrm{mm}$. film. When the pictures are projected, individual lumps of material can be recognized, against the very heterogeneous background. The location (along the axis of the tuyère) is measured by a quadruple projector arrangement of which the movements are linked. First, the two beams of a pair are made to coincide on some fixed detail in the tuyère, one on each of the projected pictures. The other two beams are then made to cross in space at the distance of the fixed detail in question, and the second pair of beams locked to the first pair. If the first pair of beams is now made to coincide with some other detail, the second pair follows its movements and intersects in space at the original distance of the new detail.

A. J. Insall (Shell Petroleum Co., Thornton le Moors) described the functions and some of the equipment of an industrial photographic section of a laboratory. One of the most important duties of such a section is to be able to repeat record photographs exactly; for this purpose arrangements must be made to locate any object precisely, to be able to duplicate the lighting arrangements and to be able to set the camera to given conditions. Records of all these settings must be kept, for it is commonly the case that photographs (for example, of pistons) require to be repeated, for comparison to be made to detect changes, sometimes at long intervals. Artistic quality (but not the technical quality) is usually unimportant, so that for recording deposits on elements of mechanisms, for example, use may be made of completely diffused lighting. Colour photography is very useful in such cases, since the additional information (on the colour) is valuable.

\section{LIBRARY CO-OPERATION IN GREAT BRITAIN}

YNDER the title "Library Co-operation in Great Britain", the report of a critical survey of the working of the National Central Library, London, and the Regional Library Bureaux, made by Mr. R. F. Vollans, deputy city librarian of Westminster, for the joint working party of the executive committee of the National Central Library and the National Committee on Regional Library Co-operation has been published*. The working party's original terms of reference were to consider methods of dealing with areas of union cataloguing at the Regional Bureaux and at the National Central Library; means of improving the efficiency of the system and its comprehensiveness; the financial requirements for coping with the present system and sources from which money can be obtained; what would be reasonable current budgets for the bureaux if this re-organization were effected; and the relationship of the union catalogues of the bureaux and the national union catalogue of the National Central Library. In deciding that the survey should be undertaken by a single individual on its behalf, the working party extended these terms of reference and instructed Mr. Vollans to deal with the coverage by each system of the libraries within its own area, co-operation within each region, the national interlending system, union catalogues, the recruitment, qualifications and superannuation of bureau staff, the financing of the regions, and adult education.

In accordance with these instructions, which were further detailed, Mr. Vollans, following an admirable historical survey, reviews in successive chapters the working of the regional library systems, inter-library loan procedure, the scope of service and reasons for non-availability of books, the provision of books to adult classes, union catalogues, subject specialization, bibliographical information, staff and finance. His generous tribute to the efficiency and enthusiasm of the staffs concerned in inter-library loans and his conviction as to the importance of such work do not prevent Mr. Vollans from frank criticisms of the weaknesses or defects he has detected, whether of abuse of procedure, of inappropriate rules or woodenness or unimaginative interpretation of either rules or procedure. To the man of science the report is of interest mainly as an account of the background against which the evolution and organization of a national or regional lending library in science and technology must be considered; but the scientist who reads it may well be led also to a keener appreciation of the difficulties and waste of time which may be caused by inaccuracy or carelessness in making requests for books or periodicals.

The survey shows that all libraries appear to be playing their part in this national inter-lending service, and the small libraries appear to contribute just as much as the larger libraries ; nor is it always the unduly large library system which provides the more expensive and more out-of-the-way books. Twenty-one university libraries and seventy-eight special libraries participate in the regional schemes, and these libraries lend more than they borrow, in that they have more specialized resources which would not find a place on the shelves of the ordinary public

* Library Co-operation in Great Britain : Report of the National Central Library and the Regional Library Bureaux. By Robert F.
Tollans. Pp. xil +139. (London: National Central Library, 1952.) $5 \mathrm{~s}$. 